\section{Implanon audit}

Madam

The short communication by Usha Kumar and colleagues $^{1}$ is a reminder of the difficulty of changing contraceptive practice in women after a termination of pregnancy (TOP). In Portsmouth we have provision of contraception fully integrated into the TOP service. Despite this there have been large numbers of women presenting for TOP with a history of at least one TOP in the past. Audit in 1994-1995 showed that 27\% of women had had at least one previous $\mathrm{TOP}^{2}$ and in 1999-2000 the equivalent figure was $26 \%$.

Implanon ${ }^{\circledR}$ is a very effective contraceptive method requiring little user compliance. This makes it potentially a good method for women who have had a TOP as the result of either failure of contraception or incorrect or inadequate use of contraception. In Portsmouth we have been offering Implanon fitting at the time of TOP since April 2002. There were reservations that fitting at this time might result in a high level of early removal and consequent waste of resources. The pre-fitting counselling is important to ensure that the side effects associated with the settling down period are tolerated. It was decided that counselling would take place at a separate appointment from the unplanned pregnancy clinic and, if possible, be done by a different clinician. The counselling is as recommended by the manufacturer and documented on a specific form.

We have undertaken an audit of removals of those fittings and a randomly selected similar number of fittings at times other than TOP. Of 38 Implanon fitted at TOP from April 2002 to February 2003, four were removed in the first 6 months (at 4, 5,11 and 23 weeks) Of 38 fitted in the usual fitting clinics, two were removed in the first 6 months (at 6 and 19 weeks). This gives a continuation rate of $89 \%$ if fitted at TOP and $95 \%$ if fitted at times other than TOP. The figures, although small, compare well with an audit of continuation rate at 6 months in community clinics $(88 \%){ }^{3}$

We feel that these data provide some reassurance that fitting of Implanon at TOP is an effective use of resources in providing accessible and reliable contraception for those most in need of it.

Jenny Bateman, MB ChB, MFFP

Associate Specialist in Contraception and Sexual Health, Contraception and Sexual Health Service, Portsmouth City Primary Care Trust, Ella Gordon Unit, St Mary's Hospital, Milton Road, Portsmouth, Hants PO1 6AE, UK. E-mail: jenny.bateman@ports.nhs.uk

References

Kumar U, Baraitser P, Morton S, et al. Decision making and referral prior to abortion: a qualitative study of women's experiences J Fam Plann Reprod Health Care 2004; 30(1)

Lewis C, Wood C, Randall S, Unplanned pregnancy: is contraceptive failure predictable? Br J Fam Plann 1996; 22 16-19.

Smith A, Reuter S. An assessment of the use of Implanon in three community services. J Fam Plann Reprod Health Care 2002; 28(4): 193-196.

\section{NEWS ROUNDUP}

\section{Locally enhanced services for contraceptive implants}

High-quality information and advice influence the continuation rates of long-acting methods of contraception. The competence of the provider is the most important factor affecting the incidence of problems of any contraceptive device.

As part of the new contract in primary care, primary care organisations (PCOs) will be deciding on bids for the insertion and removal of contraceptive implants provided as a locally enhanced service. The Faculty of Family Planning and Reproductive Health Care (FFPRHC) has drawn up recommendations for the provision of this service and will circulate this to PCOs. The locally enhanced service would include the fitting, monitoring and checking of contraceptive implants. The service offered would also include safeguards about good contraceptive practice, e.g. taking a sexual history, risk assessment, provision of condoms, equipment, and information. The document gives advice about the standards for record keeping and that annual review of the service should be undertaken. Providers would also keep a register of patients for audit and recall. It includes standards for the accreditation of health professionals as competent to provide this service and costs the service by procedure. Further information is on the FFPRHC website.

\section{Attitudes to vasectomy}

Marie Stopes International has published the results of an independent survey of attitudes towards vasectomy across Great Britain. ${ }^{1}$ They also included results from surveying their own clientele. The findings showed considerable regional variations with men from the North of England being much more likely to accept the idea of vasectomy. Men from the Midlands, Wales and Scotland were more likely to reject the idea. The survey showed that it was more likely that men would agree with the statement that 'I would consider a vasectomy' if they were more affluent or in full-time employment.

An interesting part of the survey was the number of myths believed. Men who had not had a vasectomy were more likely to give a high rating to the level of embarrassment and pain involved in having a vasectomy than those who had experienced the procedure. A quarter of men thought that vasectomies were very painful and caused a lot of swelling. One in five of the men did not know whether vasectomy reduced the level of testosterone or caused impotence (no, it doesn't). A small proportion of men $(12 \%)$ even thought vasectomy was like being castrated.

The number of men who were poorly, or wrongly, informed about vasectomy must affect the number of men willing to consider it as a good permanent method of contraception. The implications are that fuller and more accurate information about vasectomy would increase choice.

Copies of the survey are available from: Marie Stopes International, 153-157 Cleveland Street, London W1T 6QW, UK.

Views on Vasectomy: The Male Perspective. London, UK: Marie Stopes International and Ipsos UK, 2003.

\section{Adolescent-friendly health services:} an agenda for change

The World Health Organization published this document in 2003. It contains many ideas on how to plan for the development of adolescentfriendly services and includes examples from both developed and undeveloped countries. It highlights the important role that adolescents themselves can play, together with nongovernmental and governmental organisations and individuals, to improve their health and well-being. It makes a compelling case for concerted action to improve the quality - and especially the friendliness - of health services to adolescents.

The 48-page document is free of charge and can be ordered from: Department of Child and Adolescent Health and Development, World Health Organization, 20 Avenue Appia, 1211 Geneva 27, Switzerland or downloaded as a pdf document from: http://www.who.int/ reproductive-health/publications/.

\section{Inaccurate information on websites} may contribute to underuse of IUDs A report indicates that many websites about the intrauterine device (IUD) contain harmful misinformation or biased and outdated guidance. 1 The Reproductive Health Technologies Project, Washington, DC, USA surveyed 143 websites to investigate the prevalence of IUD information on general contraception websites and the quality of information on IUD-specific sites

Although all of the general contraception websites included information about the IUD, almost two-thirds were not up-to-date and around one-third presented standard product information inaccurately.

Among the IUD-specific sites, half suggested that the IUD increases the risk of pelvic inflammatory disease, without explaining that this risk is limited to the 3 weeks following insertion. More than two-thirds claimed that the device increased the risk of ectopic pregnancy and nearly one-quarter stated that the IUD was a risk to fertility. The majority failed to mention the added protective effects of the Mirena ${ }^{\circledR}$ intrauterine system.

Reference

Moore K, Weiss E. An assessment of the quality of information available on the Internet about the IUD and the potential impact on contraceptive choices. Contraception 2003; 68: 359-364.

\section{Does receiving an e-mail reminder} improve reliable pill taking?

A recent publication has reported that women like receiving an e-mail reminder, but that one in five women still miss at least one pill in each cycle. ${ }^{1}$ An e-mail reminder was sent to 50 new oral contraceptive pill users daily for 3 months. Subjects sent an e-mail reply to confirm receipt and pill taking was recorded in diaries. Four people dropped out because they did not check their e-mails daily and just under one in five others missed checking their e-mails from time to time. This bright idea cannot compensate for human forgetfulness but might be a good reminder system for someone who needs to check e-mails daily. 1 Fox MC, Creinin MD, Murthy AS, et al. Feasibility study of
the use of a daily electronic mail reminder to improve oral
contraceptive compliance. Contraception 2003; 68:
$365-371$.

\section{Chlamydia screening programme extension}

An extra $£ 4$ million, covering 50 primary care trusts (PCTs), is being invested to roll-out chlamydia screening programmes. It will mean that one-quarter of all PCTs will be providing screening to at-risk groups.

The chlamydia screening programme will primarily target women aged under 25 years who access sexual health services, however a greater uptake of testing among men will also be promoted.

A review of how genitourinary medicine (GUM) clinics are modernising will also take place. Since $2002, £ 35$ million has been invested in GUM clinics to help them modernise and reduce waiting times.

Further information is available at http://www.doh.gov.uk/sexualhealthandhiv/

Reviewed by Gill Wakley, MD, MFPP Visiting Professor in Primary Care Development, Staffordshire University and Freelance General Practitioner and Writer, Abergavenny, UK 